Soon-Seok Song

Sang-Hyun Kim*

Kwang-Jun Paik

http://dx.doi.org/10.21278/brod70402

ISSN 0007-215X

eISSN 1845-5859

\title{
DETERMINATION OF LINEAR AND NONLINEAR ROLL DAMPING COEFFICIENTS OF A SHIP SECTION USING CFD
}

UDC 629.5.017.22

Original scientific paper

\begin{abstract}
Summary
The most prevalently used method to obtain the nonlinear roll damping coefficient is the free roll decay test. However, this method can only be conducted at the resonance frequency and thus cannot consider the effect of the frequency. This is a certain limitation as the resonance frequency can be changed at any time by the ship's loading conditions. Therefore, it is worth investigating the frequency dependency of the nonlinear roll damping coefficients. In this study, a numerical method was proposed to derive the linear and nonlinear roll damping coefficients of ships at different frequencies. Fully nonlinear CFD simulations of forced harmonic roll motion were conducted and the roll damping coefficients were calculated. Then, the damping coefficients were decomposed into the linear and nonlinear components using the linear regression analysis. The linear roll damping coefficients were compared with potential coefficients and showed a good agreement, while the nonlinear roll damping coefficients were compared with the coefficients calculated using a semi-empirical method. The nonlinear roll damping coefficients calculated from the proposed method showed a strong frequency dependency. Finally, possible rationales for the frequency dependence of the nonlinear roll damping coefficient were investigated.
\end{abstract}

Key words: $\quad$ Nonlinear roll damping; computational fluid dynamics; ship motion; forced oscillation

\section{Introduction}

A ship's motion in waves affects the habitability and safety of the ship, as well as the operation of equipment and various other activities. Especially roll motion, among the six degrees of freedom motions of ships, is critical as far as ship stability is concerned. The resonance phenomena of the roll motion are associated with problems of instabilities (e.g. synchronous rolling and parametric rolling). Synchronous rolling usually occurs at beam seas when the encounter wave period is close to the natural roll period. Parametric rolling, on the 
other hand, often occurs on following and quartering seas. It is caused by inducing instability and an increase in rolling amplitude due to the periodic variation of stability characteristics [1]. For the many years, parametric rolling was considered as an unlikely occurrence, but its importance started to be highlighted after the incident from 1998 when a post-Panamax container ship experienced extreme rolling due to this phenomenon. Since that time, a large number of efforts have been devoted to investigating the features of parametric rolling [1-8].

These resonant phenomena can also occur in other modes if some specific conditions are met. Non-conventional vessels such as SWATH (small-waterplane-area twin hull), whose the restoring capabilities in pitch are not high as those of conventional mono-hulls, can experience resonant motions when the vessel is heaving and pitching $[9,10]$. Resonant phenomena can also take place by trapped water between two vertical walls e.g. moonpools [11], ship moored by a bottom mounted terminal [12], or multi-hull configurations [13].

Predicting the ship motions using traditional linear potential flow based solutions can bring sufficient accuracies for most of the modes of motions, due to their weak nonlinearities. However, it is well known that roll damping has strong nonlinearity due to the high contribution of viscous roll damping [2]. Therefore, nonlinear roll damping coefficients should be taken into account for better predictions. Accordingly, a large number of studies have been devoted to the derivations of the nonlinear roll damping coefficients [2, 14-20].

The free roll decay test is one of the most prevalently used methods to determine the nonlinear roll damping coefficients. This method has a simple test procedure and thus simple test equipment. However, it can only be used at the natural frequency of the floating body and cannot provide information about the relation between the damping coefficients and the frequencies of roll motion. This can be a limitation considering that the ships' natural frequency can always vary by the loading conditions.

On the other hand, the forced harmonic oscillation test can be used to derive damping coefficients and the added mass or added moment of inertia coefficients of all six degrees of freedom. This method can be performed at arbitrary frequencies and amplitudes. This method involves measurements of the hydrodynamic and hydrostatic loads acting on the body while it is forced to oscillate at a selected frequency and amplitude. The coefficients are obtained by decomposing the measured hydrodynamic forces into in-phase and out-phase.

However, there are critical difficulties for forced roll oscillations, as asserted by Vugts [21]. The pure sinusoidal oscillation is not achievable due to the interference of hydrodynamic loads induced by the motion itself. Second, the magnitude of the damping moment is relatively small, compared to other moment components measured together (i.e. the added moment of inertia, restoring moment, and the moment of inertia of the model itself), such that small measurement error can lead to large uncertainties in the calculated damping coefficients.

Recently, with the rapid growth of computational power, there have been increasing number of studies utilizing Computational Fluid Dynamics (CFD) for the derivations of roll damping coefficients. These studies involve either the simulations of free roll decay motions [22-26] or forced harmonic motions [27-36].

The studies using free roll decay simulations [22-26] show good agreements with the experimental results. However, these studies also have the same limitation that the simulation can only be performed at the natural frequencies of the ships, as they use the same mechanism as the physical free roll decay test.

On the other hand, the CFD simulations involving forced motions [27-36] are free from this limitation as the simulations can be performed at arbitrary frequencies. And also many of the above-mentioned difficulties of the forced oscillation tests can be omitted. That is to say, the pure sinusoidal oscillation is achievable in the simulations and the results are free from the 
measurement errors. However, none of these studies investigate the frequency dependence of the nonlinear roll damping coefficients.

The literature suggests that there exists no specific study determining the nonlinear roll damping coefficient at various frequencies to investigate the frequency dependence. One may argue that the most critical motions occur at their resonance frequencies and thus it is enough using a constant nonlinear roll damping coefficient, which is obtained from a roll decay test. However, the resonance frequencies of ship roll motions can always vary by the loading conditions. That means the nonlinear roll damping coefficient obtained from the free roll decay test cannot necessarily represent the nonlinear roll damping coefficients at different loading conditions. Accordingly, it is worth investigating the frequency dependence of the nonlinear roll damping coefficients for better understanding of ship motions in waves.

Therefore, the aim of this study is to fill the literature gap by developing a CFD model to simulate forced harmonic roll motions and performing a comprehensive investigation into the behaviors of linear and nonlinear roll damping coefficients at different frequencies.

In this study, a series of CFD simulations of forced harmonic roll with varying roll amplitudes and frequencies. The roll damping coefficients including the viscous effects were obtained from the simulations. For validation purposes, the results were compared with experimental data from a free roll decay test and a forced oscillation test. Then, the obtained roll damping coefficients were decomposed into the linear and nonlinear (quadratic) components using the linear regression analysis. The linear roll damping coefficient showed good agreement with the potential roll damping coefficients calculated using the close-fit conformal mapping. The nonlinear roll damping coefficients showed a decreasing trend with the frequencies. A possible rationale behind the frequency dependency was presented.

\section{Methodology}

\subsection{Motion equation}

The roll motion equation with a quadratic damping term is,

$$
\left(I_{x x}+A_{44}\right) \ddot{\phi}+B_{44 l} \dot{\phi}+B_{44 v}^{(2)}|\dot{\phi}| \dot{\phi}+C_{44} \phi=F_{4}
$$

where $\ddot{\phi}, \dot{\phi}$, and $\phi$ are the angular acceleration, angular velocity, and angular displacement of roll motion, respectively. $I_{x x}$ and $A_{44}$ are the moment of inertia and the added moment of inertia in rolling. $B_{44 l}$ and $B_{44 v}^{(2)}$ are the linear and nonlinear (viscous) roll damping coefficients, and the superscript (2) indicate that his coefficient is used in a quadratic term $\left(B_{44 v}^{(2)}|\dot{\phi}| \dot{\phi}\right) . C_{44}$ is the restoring coefficient, which can be calculated using Equation 2

$$
C_{44}=\rho g \nabla \overline{G M} \tan \phi
$$

where, $\rho, g, \nabla$, and $\overline{G M}$ are the density of water, gravitational acceleration, the displacement volume, and the metacentric height of the body, respectively. The quadratic damping term in Equation 1 can be linearized by the following equations,

$$
\begin{gathered}
\left(I_{x x}+A_{44}\right) \dot{\phi}+\left(B_{44 l}+B_{44 v}^{(1)}\right) \dot{\phi}+C_{44} \phi=M_{\text {roll }} \\
B_{44 v}^{(1)}=\frac{8}{3 \pi} \phi_{a} \omega B_{44 v}^{(2)}
\end{gathered}
$$


in which, the superscript (1) and (2) indicate the orders of the term, i.e. $B_{44 v}^{(1)}$ is the linearized viscous damping coefficient, whereas $B_{44 v}^{(2)}$ is the viscous damping in quadratic form. $\phi_{a}$ and $\omega$ are the roll amplitude and the roll frequency, respectively.

\subsection{Forced harmonic roll motion}

In the simulations, the body was forced to roll with the roll amplitude, $\phi_{a}$, and the frequency, $\phi_{a}$. The time-dependent forced roll motion is given as,

$$
\phi=\phi_{a} \cos (\omega t)
$$

The hydrodynamic moment can be obtained by subtracting the restoring moment $\left(C_{44} \phi\right)$ from the total moment acting on the body. The time-dependent hydrodynamic moment, $M$, can be written as,

$$
M=M_{a} \cos (\omega t-\varepsilon)
$$

where, $M_{a}$ is the amplitude of the hydrodynamic moment and $\varepsilon$ phase shift with respect to the roll motion. Figure 1 schematically illustrates the hydrodynamic moment obtained from the forced roll simulations.

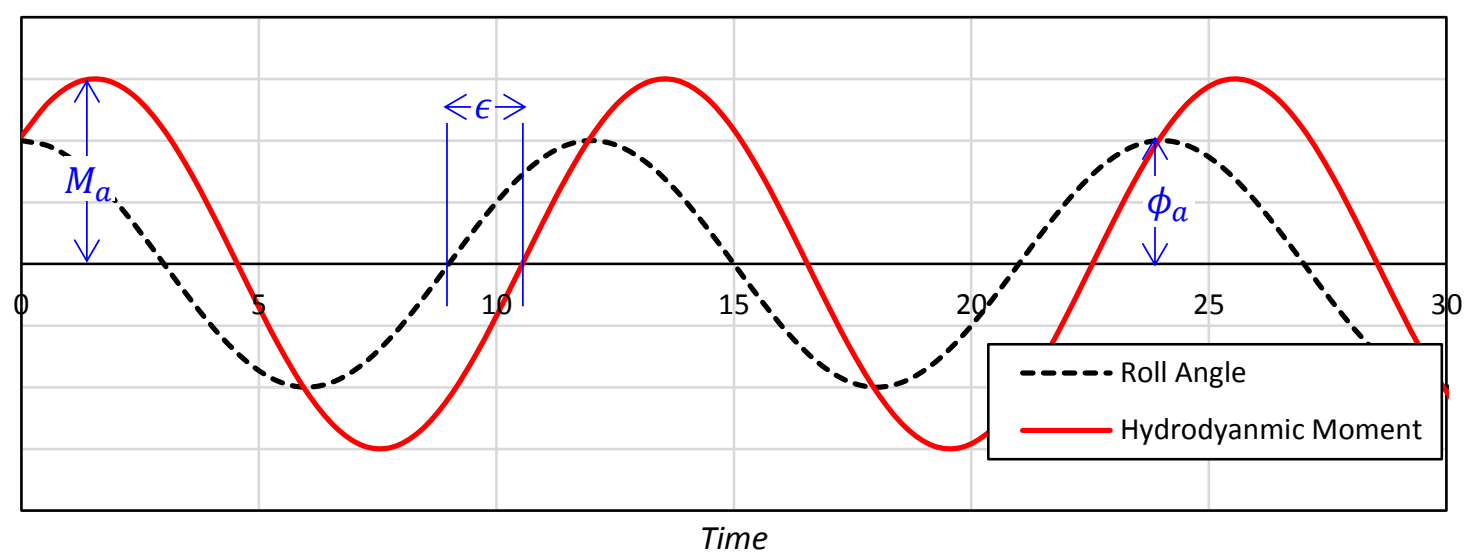

Fig.1 Hydrodynamic moment acting on the body

The obtained hydrodynamic moment can be divided by the in-phase, $M_{i n}$, and out-phase, $M_{\text {out }}$, as follows.

$$
\begin{gathered}
M_{a} \cos (\omega t-\varepsilon)=M_{\text {in }} \cos (\omega t)+M_{\text {out }} \sin (\omega t) \\
M_{\text {in }}=M_{a} \cos (\varepsilon) \\
M_{\text {out }}=M_{a} \sin (\varepsilon)
\end{gathered}
$$

Then the added moment of inertia, $A_{44}$, and the roll damping coefficient, $B_{44}$, can be determined as

$$
A_{44}=\frac{M_{\text {in }}}{\phi_{a} \omega^{2}}
$$




$$
B_{44}=\frac{M_{\text {out }}}{\phi_{a} \omega}
$$

It is of note that the damping coefficients, $B_{44}$, obtained from the forced roll simulations include the viscous roll damping coefficients $\left(B_{44}=B_{44 l}+B_{44 v}^{(1)}\right)$. Therefore, the magnitudes of $B_{44}$ obtained from the forced roll simulations varies with the amplitudes, due to the nonlinearity of the viscous roll damping.

\subsection{Linear and Nonlinear Damping Components}

In this study, the forced roll simulations were conducted at varying amplitudes, $\phi_{a}$, at each frequency. Then, the obtained roll damping coefficients, $B_{44}$, varies with the roll amplitudes due to the nonlinearity, as mentioned earlier. The obtained $B_{44}$ values can be divided into the linear and nonlinear components using a linear regression method, as schematically illustrated in Figure 2. Using the intercept, $\alpha$, and the slope, $\beta$, of the linear trend line of the $B_{44}$ values varying with the amplitudes, the linear and nonlinear roll damping coefficients are determined as,

$$
\begin{gathered}
B_{44}=\alpha+\beta \phi_{a} \\
B_{44 l}=\alpha \\
B_{44 v}^{(2)}=\frac{3 \pi}{8 \omega} \beta
\end{gathered}
$$

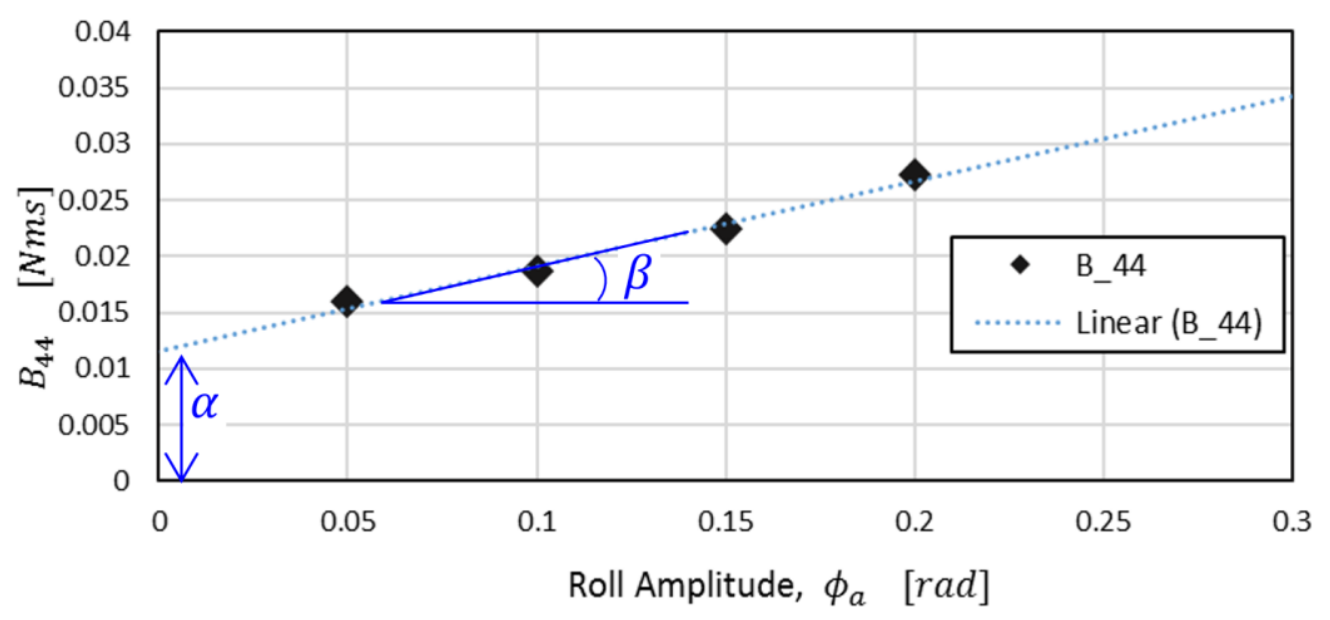

Fig.2 Roll damping coefficients at different roll amplitudes of oscillation

\subsection{Numerical modelling}

The proposed CFD model was developed based on the unsteady Reynolds-averaged Navier-Stokes (URANS) method using a commercial CFD software package, STAR-CCM+. The simulations were modelled in two dimensions (2D) to minimise the computational cost. Mesh generation was performed using the built-in automated meshing tool of STAR-CCM+. Trimmed hexahedral meshes were used. A prism layer was used around the body surface as shown in Figure 3. 


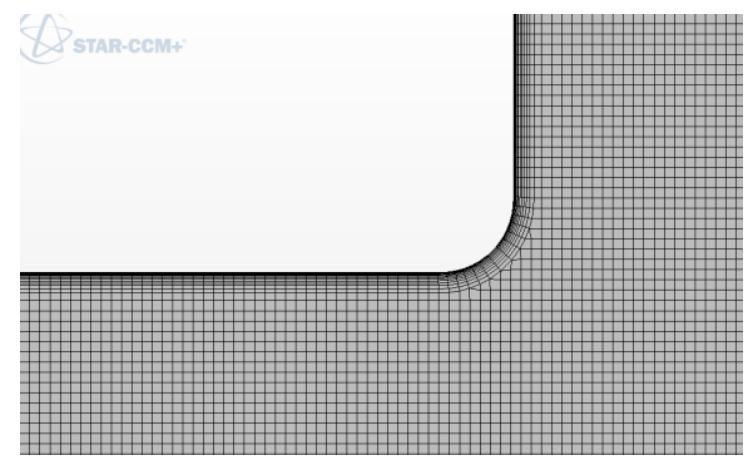

Fig.3 Prism layers on the body surface

Figure 4 illustrates the computational domain used for the simulations. The overset-mesh technique was used to simulate the forced roll motions. Both the sides of the basin were modelled with slopes, such that they induce the waves to break. The boundary conditions for the rotating body and the bottom and sides of the tank were defined as no-slip walls, while the top of the computational domain was set to pressure outlet boundary condition.

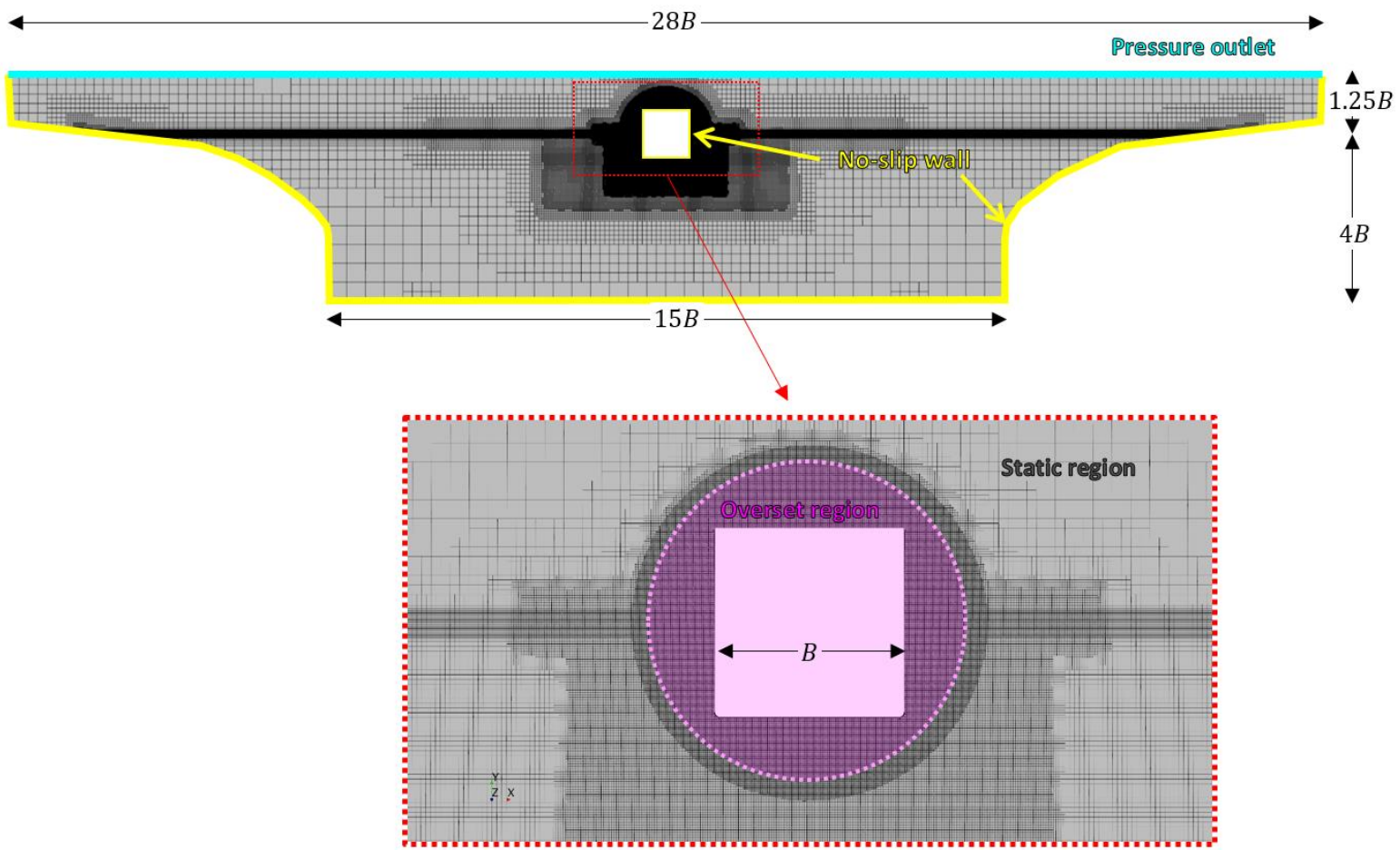

Fig.4 Computational domain and the boundary conditions

The volume of fluid (VOF) method was used for the free surface, and the $k-\epsilon$ model was selected as the turbulence model. The physics continua used in this study are given in Table 1. 
Table 1 Physics continua used for the simulation

\begin{tabular}{|c|l|}
\hline \multicolumn{1}{|c|}{ Physics continua } & \multicolumn{1}{c|}{ Model } \\
\hline Time & Implicit Unsteady \\
\hline \multirow{2}{*}{ Material } & $\begin{array}{l}\text { Eulerian Multiphase } \\
\text { Multiphase Interaction }\end{array}$ \\
\hline \multirow{2}{*}{ Eulerian Multiphase Model } & Volume of Fluid (VOF) \\
& Multiphase Equation of state \\
& Segregated Flow \\
\hline \multirow{2}{*}{ Viscous Regime } & Turbulent \\
\hline Reynolds-Averaged & Reynold-Averaged Navier-Stokes \\
\hline Turbulence & K-Epsilon Turbulence \\
\hline
\end{tabular}

\section{Results}

\subsection{Validation study}

\subsubsection{Validation case 1}

For the validation of the CFD model at different frequencies, the obtained damping coefficients were compared with the experimental results of forced harmonic oscillation tests performed by Vugts [21]. The heave and roll damping coefficients were compared for the validation. Figure 5 and Table 2 show the specifications of the model.

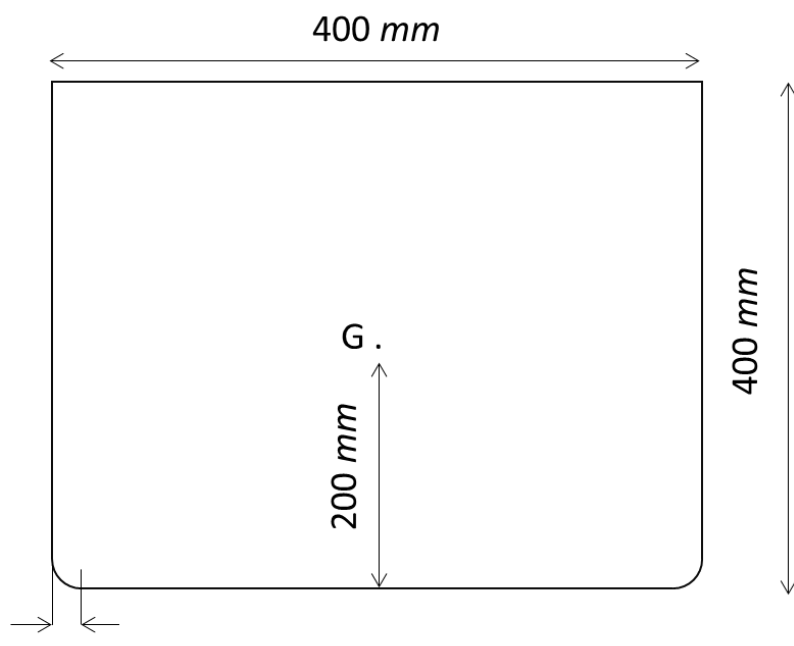

$12.5 \mathrm{~mm}$

Fig.5 Cross section of the model for validation case 1

Figure 6 compares the heave damping coefficients obtained from the current CFD simulations and the experimental results of Vugts [21]. The simulations were conducted at the frequency range of $\omega \sqrt{B / 2 g}=0.3-1.4$ with three different heave amplitudes. The 
corresponding Reynolds number range for the simulations are $R e_{B}=9.4 \times 10^{3}-1.1 \times 10^{5}$ (based on the peak velocity and the breadth of the ship section).

Table 2 Principal dimensions of model for validation case 1

\begin{tabular}{|l|l|}
\hline Item & Dimension \\
\hline Length, $L$ & $4.19 \mathrm{~m}$ \\
\hline Breadth, $B$ & $400 \mathrm{~mm}$ \\
\hline Depth, $D$ & $400 \mathrm{~mm}$ \\
\hline Draft, $d$ & $200 \mathrm{~mm}$ \\
\hline Bilge radius, $r$ & $12.5 \mathrm{~mm}$ \\
\hline Displacement, $\Delta$ & $335.2 \mathrm{~kg}$ \\
\hline$\overline{K B}$ & $100 \mathrm{~mm}$ \\
\hline$\overline{B M}$ & $65.1 \mathrm{~mm}$ \\
\hline$\overline{K G}$ & $200 \mathrm{~mm}$ \\
\hline$\overline{G M}$ & $-33.33 \mathrm{~mm}$ \\
\hline
\end{tabular}

As shown in the figure, a good agreement achieved between the current CFD and the experimental data.

On the other hand, deviations were observed for the roll damping coefficients. Figure 7 shows the roll damping coefficients, obtained from the current CFD simulations and the Vugts' forced harmonic oscillation test. The simulations were conducted at the frequency range of $\omega \sqrt{B / 2 g}=0.3-1.5$ with three different roll amplitudes. The corresponding Reynolds number range for the simulations are $R e_{B}=9.4 \times 10^{3}-1.1 \times 10^{5}$ (based on the peak peripheral velocity at the bilge and the breadth of the ship section). The roll damping coefficients show a fair agreement for low and moderate frequencies but the deviations increase with the frequency. Similar differences were also observed by other studies [18-21]. These discrepancies may be attributed to experimental inaccuracies at the high frequency of motions, as also questioned by Vugts [21], Bonfiglio [31] and Thilleul et al. [32]. However, further investigations are required in future studies for better understandings.

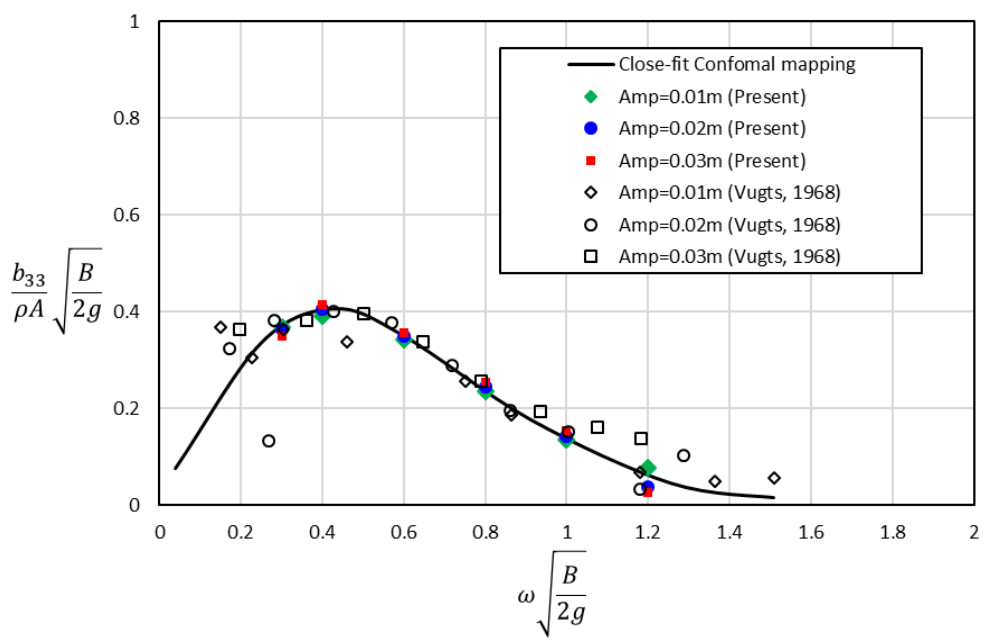

Fig.6 Heave damping coefficients at different frequencies and amplitudes 


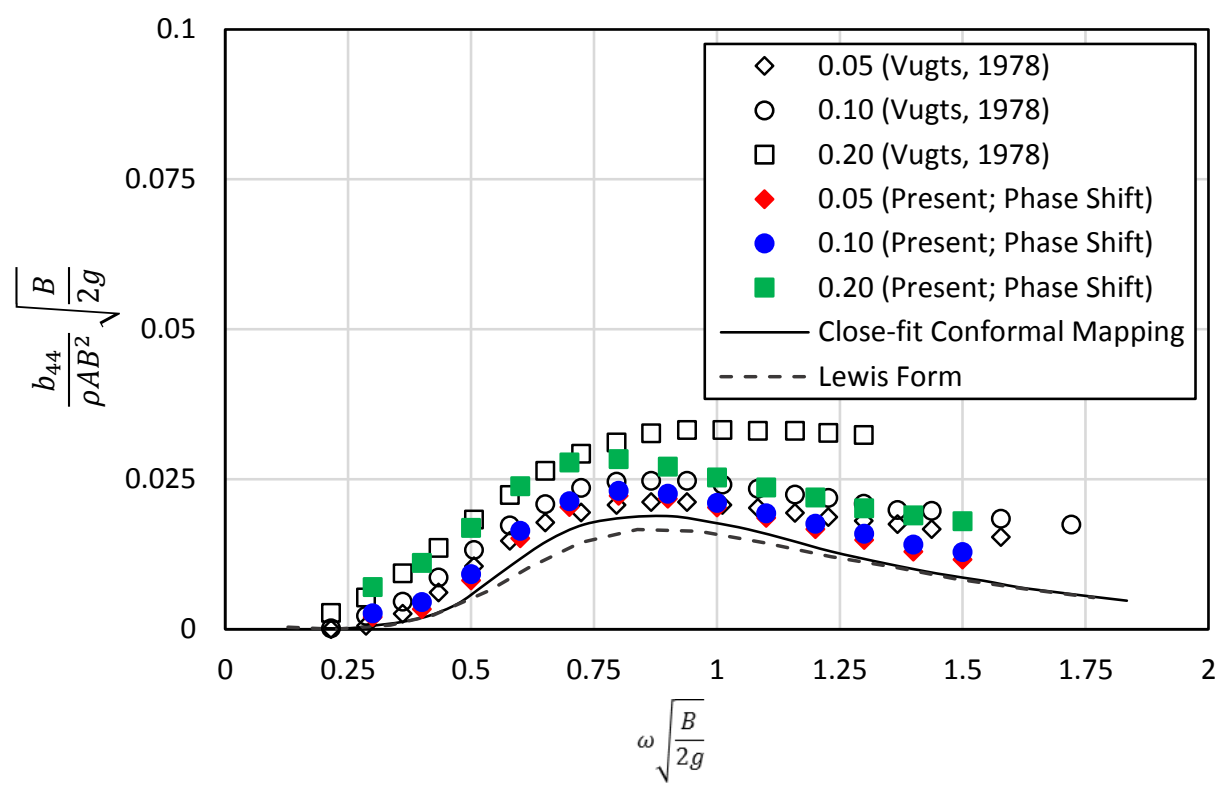

Fig.7 Roll damping coefficients at different frequencies and amplitudes, at roll amplitudes of 0.05, 0.10, and $0.20 \mathrm{rad}$

\subsubsection{Validation case 2}

An additional validation study was performed comparing the simulation results with the free roll decay test conducted by Kim et al. [20]. Figure 8 and Table 3 show the specifications of the model.

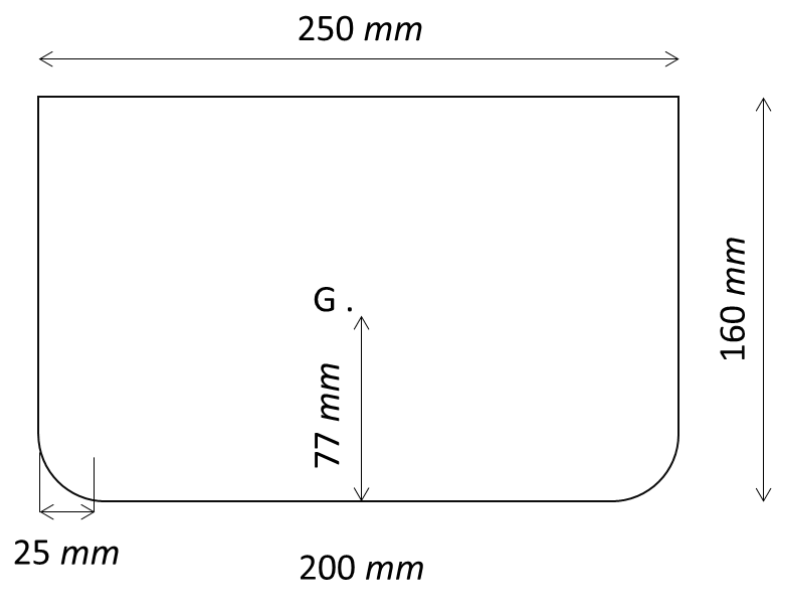

Fig.8 Cross section of the model for validation case 2

Figure 9 compares the roll damping coefficients calculated from the current simulations and the scatter diagrams obtained from the free roll decay test performed by Kim et al. [20]. The coefficients in the figure are non-dimensionalised as the ratios to the critical damping coefficients $\left(B_{44}^{\prime}=B_{44} / B_{c r}\right)$. As can be seen in the figure, a good agreement was achieved between the roll damping coefficients obtained from the current simulations and the experimental results of Kim et al. [20]. 
Table 3 Principal dimensions of the model for validation case 2

\begin{tabular}{|l|l|}
\hline Item & Dimension \\
\hline Length, $L$ & $1000 \mathrm{~mm}$ \\
\hline Breadth, $B$ & $250 \mathrm{~mm}$ \\
\hline Depth, $D$ & $160 \mathrm{~mm}$ \\
\hline Draft, $d$ & $80 \mathrm{~mm}$ \\
\hline Bilge radius, $r$ & $25 \mathrm{~mm}$ \\
\hline Displacement, $\Delta$ & $19.73 \mathrm{~kg}$ \\
\hline$\overline{K B}$ & $41.5 \mathrm{~mm}$ \\
\hline $25 \overline{B M}$ & $65.1 \mathrm{~mm}$ \\
\hline$\overline{K G}$ & $77 \mathrm{~mm}$ \\
\hline$\overline{G M}$ & $29.6 \mathrm{~mm}$ \\
\hline Critical damping coefficient, $B_{c r}$ & $5.73 \mathrm{~N} \cdot \mathrm{m} \cdot \mathrm{s}$ \\
\hline
\end{tabular}

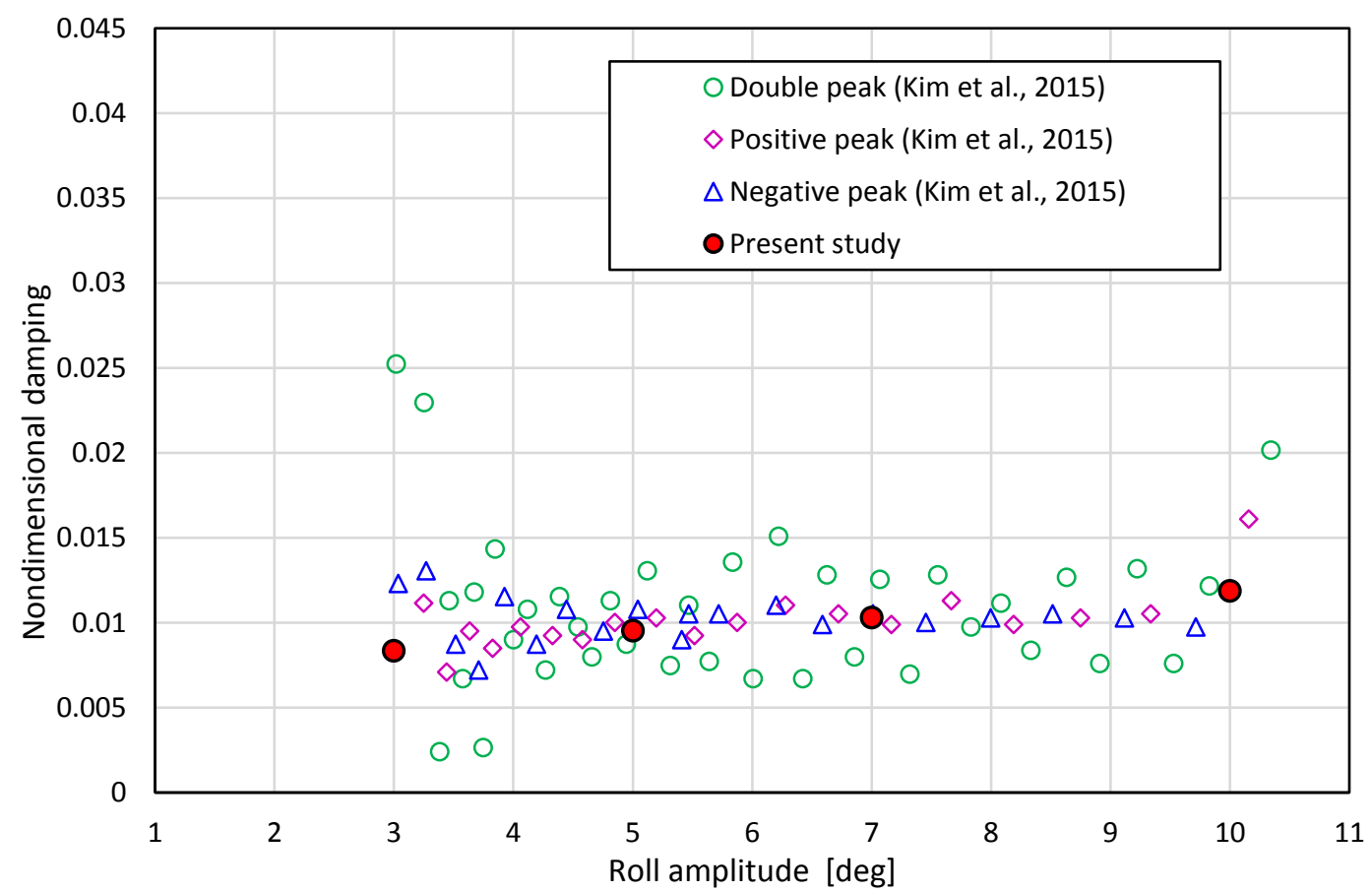

Fig.9 Roll damping coefficients obtained in the present study and from a scatter diagram by Kim et al. [20]

\subsection{Determination of the linear and nonlinear roll damping coefficients}

To examine the effect of frequency on the nonlinear roll damping coefficient, the linear and nonlinear roll damping coefficients were calculated using the proposed method. For the calculations, the damping coefficients obtained for validation case 1 were used. The coefficients obtained at different amplitudes at each frequency were decomposed into linear and nonlinear damping coefficients using Equation 12-14. Figure 10 shows the calculated linear and nonlinear roll damping coefficients using the proposed method. Both the linear and nonlinear coefficients show strong frequency dependencies. 


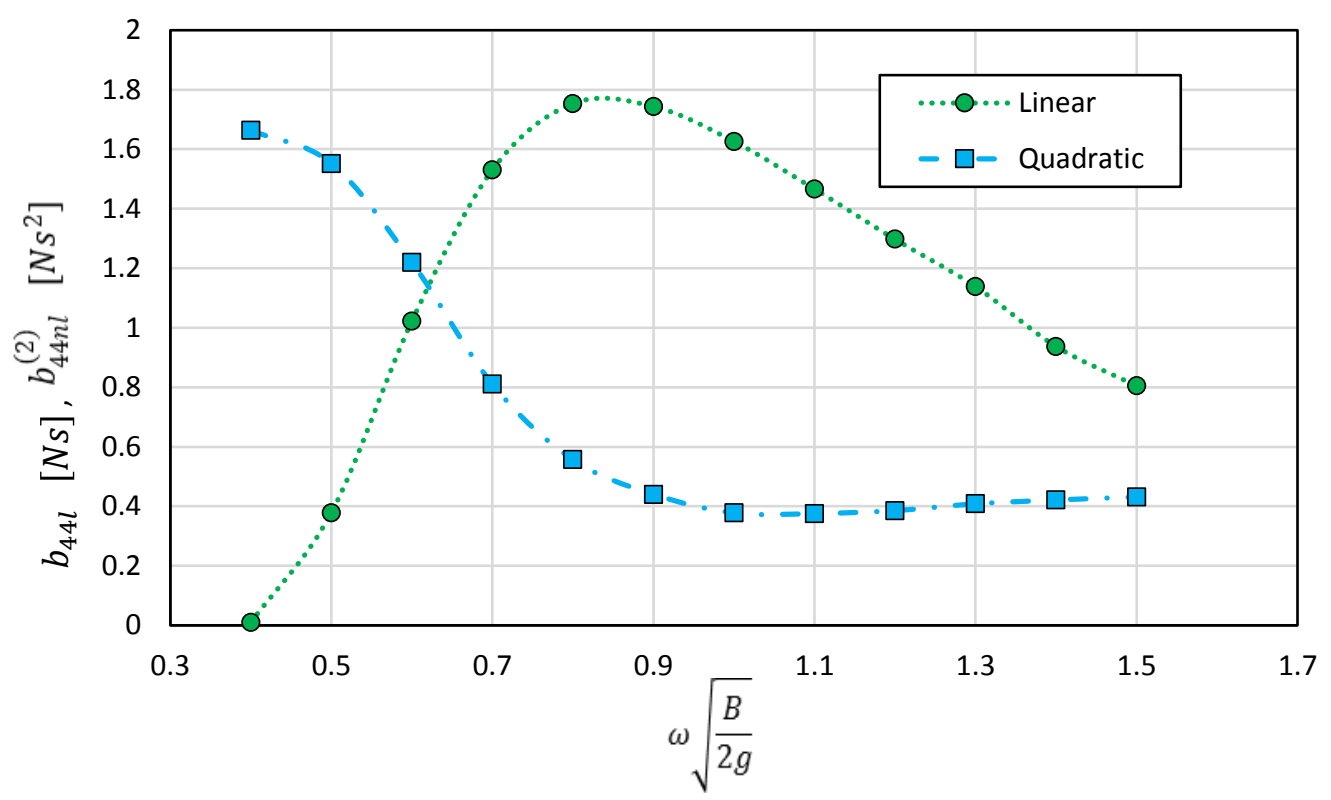

Fig.10 Linear and nonlinear roll damping coefficients obtained from the present study

\subsection{Linear roll damping coefficient}

Figure 11 compares the linear roll damping coefficients calculated by the newly proposed method and the linear potential damping coefficients obtained by close-fit conformal mapping. As shown in the figure, a good agreement was achieved between the linear roll damping coefficients obtained from the different methods.

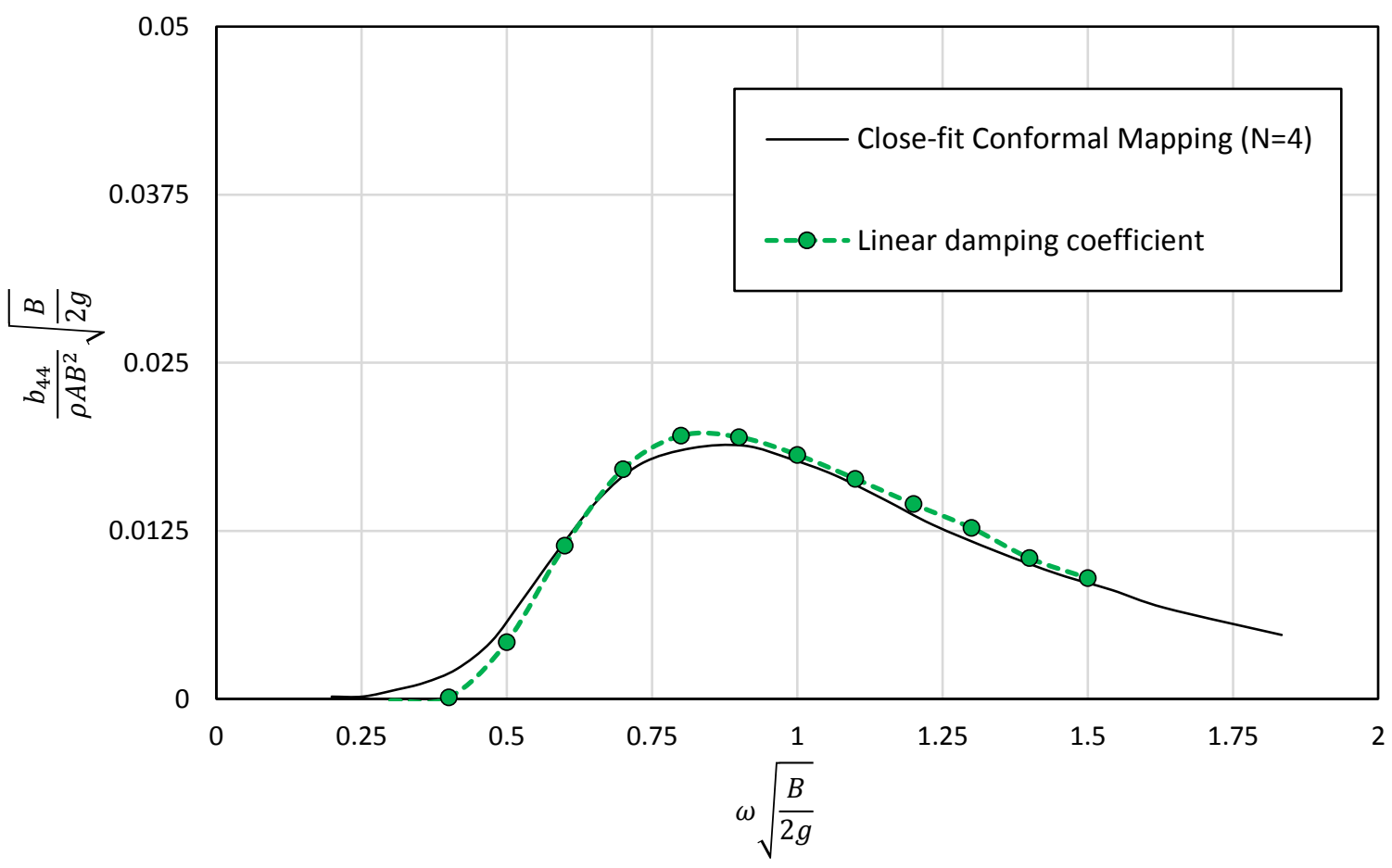

Fig.11 Linear roll damping coefficients obtained from the present study and potential theory 


\subsection{Nonlinear roll damping coefficient}

The nonlinear (quadratic) roll damping coefficients obtained at the different frequencies were compared with a semi-empirical method. Ikeda [17] described the nonlinear roll damping coefficient using four components, namely; frictional damping, eddy-making damping, bilgekeel damping, and lift damping. In this study, only the frictional and eddy-making components were considered as there is no bilge-keel or advance speed in this study. Equation 13 shows the quadratic roll damping coefficient calculated by Ikeda's method as,

$$
B_{44 q}^{(2)}=B_{44 F}^{(2)}+B_{44 E}^{(2)}
$$

Figure 12 compares the quadratic damping coefficients which were obtained from the proposed method and those calculated by Ikeda's method. It can be seen from the figure that the quadratic damping coefficients obtained from the current study show a strong frequency dependence while those from Ikeda's method remain relatively consistent. Considering that eddy-making damping has large contributions in the quadratic damping coefficients in Ikeda's method, as shown in the figure, the difference between two methods can be attributed to eddymaking damping. That is to say, whereas Ikeda's method does not consider the effect of frequency when calculating the eddy-making damping coefficients, if the eddy-making behavior of the current CFD simulation has frequency dependency, this can bring different results.

For confirmation purposes, the roll damping components of the CFD simulations were divided into frictional (shear) and pressure to investigate the contributions of the different damping components. Figure 13 and 14 compare the contributions of the shear and pressure components in the damping coefficients, at low $\left(\omega^{\prime}=0.5\right)$ and high $\left(\omega^{\prime}=1.5\right)$ frequencies respectively.

As illustrated in the figures, the pressure components were observed to be dominant. They are nonlinear with respect to the roll amplitude. The nonlinearity of the damping coefficients (i.e. changes with the roll amplitude) was observed to be larger at low frequencies (Figure 13) compared to them at high frequencies (Figure 14). As the nonlinearity of the wave making damping is expected to be minor [37], this frequency dependence can be mostly attributed by the eddy-making damping.

As a result, the quadratic roll damping coefficients calculated from the newly proposed method show disagreement with those obtained from Ikeda's method, which does not consider the effect of frequency on the eddy-making damping. 


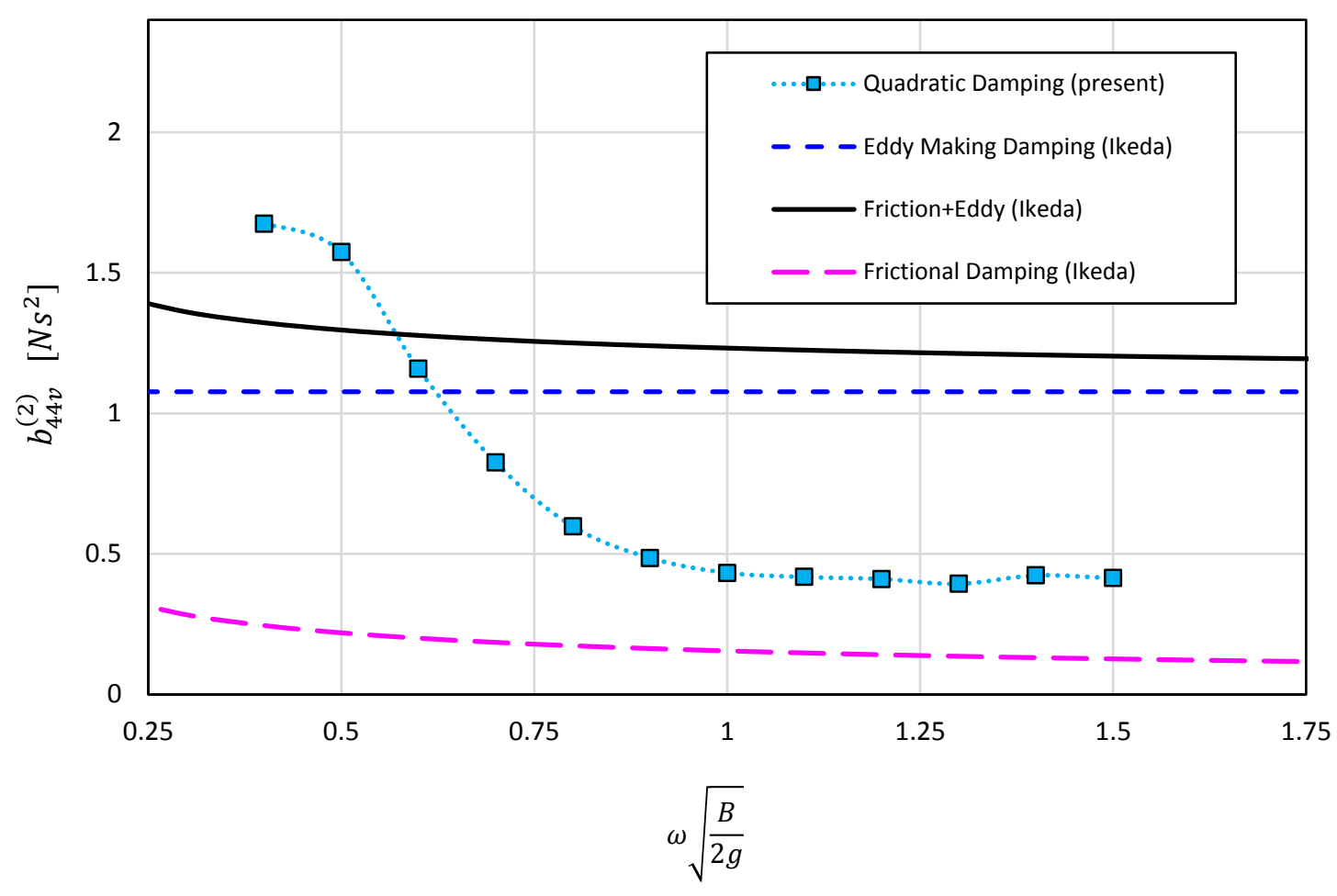

Fig.12 Quadratic roll damping coefficients obtained by the present study and Ikeda's method

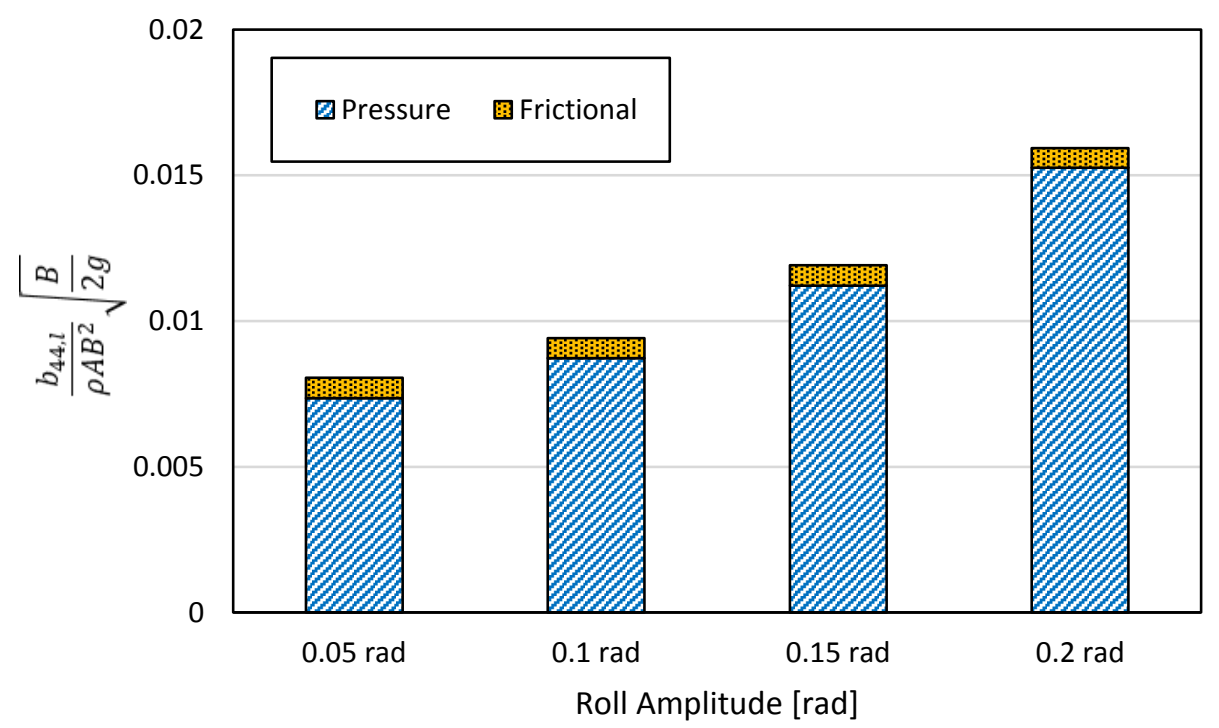

Fig.13 Pressure and shear component of damping moment at $\omega^{\prime}=0.5$ 


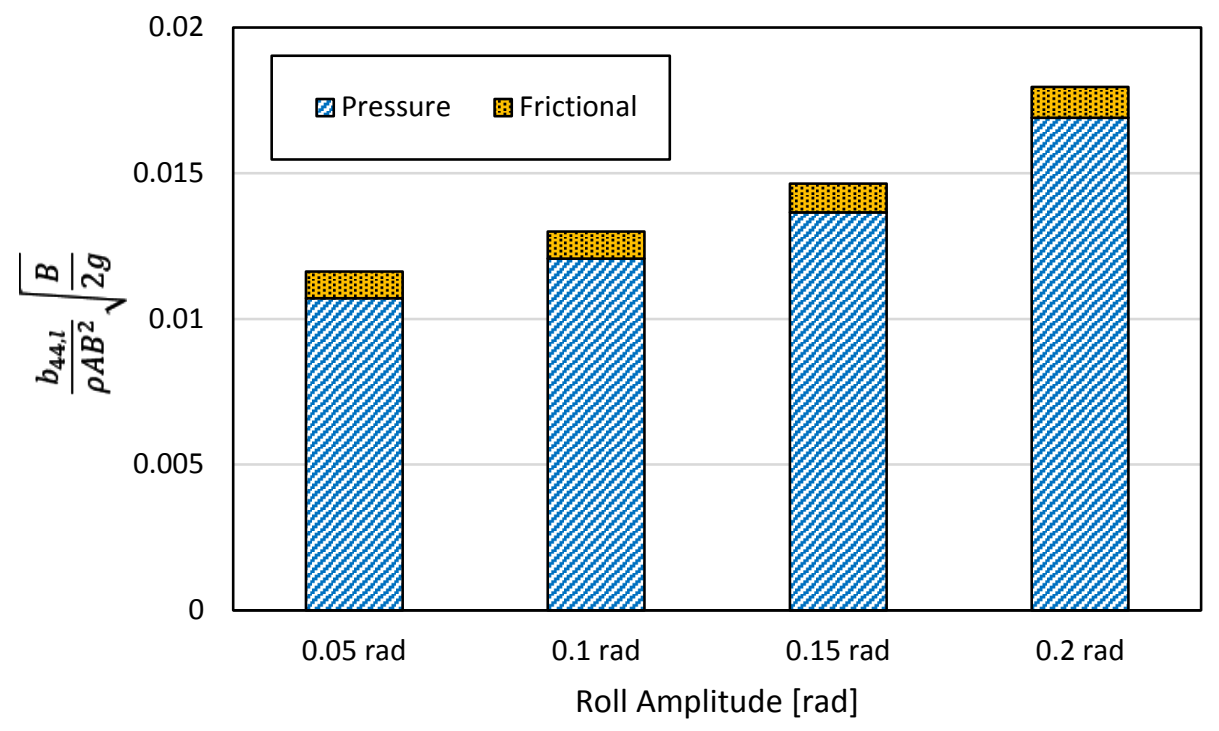

Fig.14 Pressure and shear component of damping moment at $\omega^{\prime}=1.5$

In order to investigate the rationale behind the frequency dependency of eddy-making damping, the vortex field around the body was compared. Figures 15 (a) and (b) compares the vorticity around the body with respect to motion amplitudes of 0.05 and 0.15 rad at a frequency of $\omega=3.5 \mathrm{rad} / \mathrm{s}(\omega \sqrt{B / 2 g}=0.5$, while Figures 15 (c) and (d) show the those at $\omega=$ $10.5 \mathrm{rad} / \mathrm{s}(\omega \sqrt{B / 2 g}=1.5)$. As shown in the figure, the vorticity magnitude increase with both the roll amplitude and frequency, but the influence from the roll amplitude (a vs b, c vs d) is much greater than that on the frequency ( $\mathrm{a}$ vs c, b vs d).

On the other hand, it should be borne in mind that the roll damping coefficient is the ratio between the radiation moment in out phase, $R_{\text {out }}$, and the roll rate, $\dot{\phi}_{a}=\phi_{a} \omega$. Therefore, comparing the vorticity magnitudes at the same roll rate, $\left(\dot{\phi_{a}}=\phi_{a} \omega\right)$ can be a good measure to investigate the frequency dependency on eddy-making damping. That is to say, Figure (b) and (c) have the same roll rate $\left(\dot{\phi}_{a}=0.53 \mathrm{rad} / \mathrm{s}\right)$, and thus the vorticity magnitudes of them can represent the level of eddy-making damping at the frequencies of $\omega=3.5 \mathrm{rad} / \mathrm{s}$ and $\omega=$ $10.5 \mathrm{rad} / \mathrm{s}$, respectively. As can be seen in the figure, the vorticity in Figure (b) is much greater than that in Figure (c). It is thought that because the vorticity increases more with roll amplitude than with frequency, as mentioned earlier, (b) shows larger vorticity magnitude due to its larger amplitude although it has smaller oscillation frequency than (c).

Therefore, it can be concluded that at a constant roll rate, the corresponding roll amplitude decreases when the frequency increases $\left(\phi_{a}=\dot{\phi}_{a} / \omega\right)$. As a consequence, the vorticity around the body decreases and thus the eddy-making damping decreases, resulting in the decreasing trend of the quadratic roll damping coefficients. Since Ikeda's method does not consider these influences of frequency, the Ikeda's quadratic roll damping coefficients show disagreement with those obtained from the newly proposed method. 


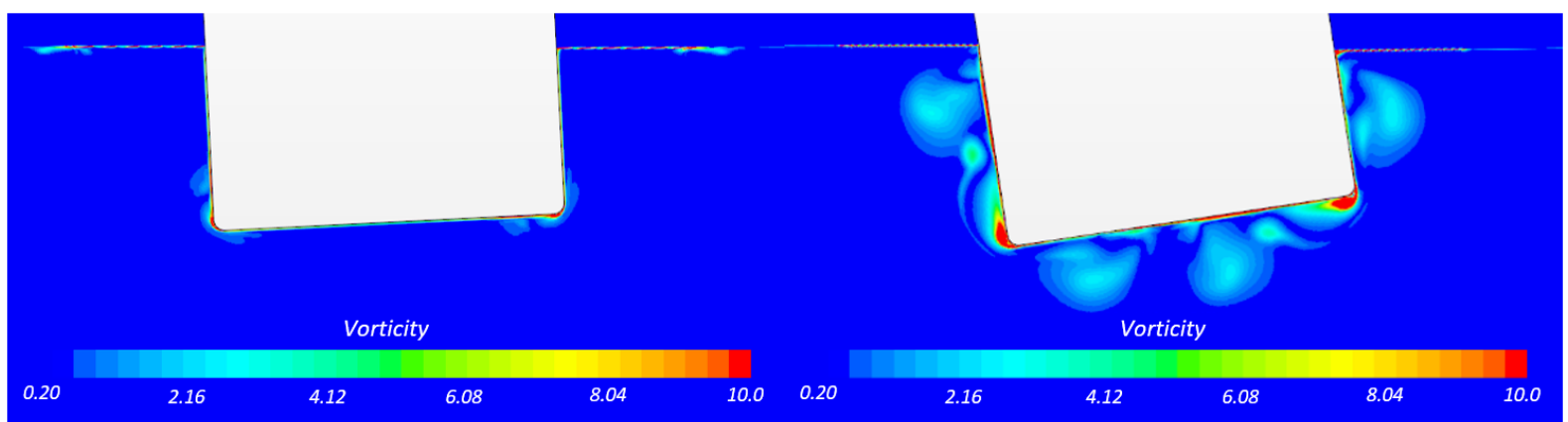

(a) $\omega=3.5 \mathrm{rad} / \mathrm{s}, \phi_{a}=0.05 \mathrm{rad}, \dot{\phi_{a}}=0.18 \mathrm{rad} / \mathrm{s}$

(b) $\omega=3.5 \mathrm{rad} / \mathrm{s}, \phi_{a}=0.15 \mathrm{rad}, \dot{\phi_{a}}=0.53 \mathrm{rad} / \mathrm{s}$

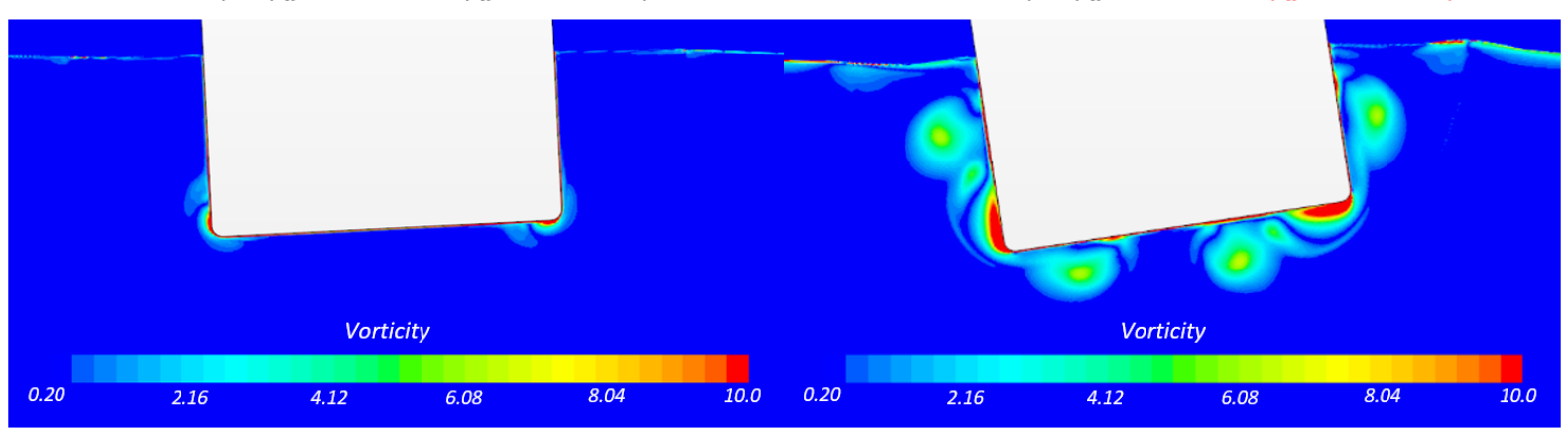

(c) $\omega=10.5 \mathrm{rad} / \mathrm{s}, \phi_{a}=0.05 \mathrm{rad}, \dot{\phi_{a}}=0.53 \mathrm{rad} / \mathrm{s}$

(d) $\omega=10.5 \mathrm{rad} / \mathrm{s}, \phi_{a}=0.15 \mathrm{rad}, \dot{\phi_{a}}=1.58 \mathrm{rad} / \mathrm{s}$

Fig.15 Vorticity around the cross section at different frequencies

\section{Conclusion}

In this study, a new approach was proposed to determine the linear and nonlinear roll damping coefficients with varying frequencies. A fully nonlinear CFD simulation model for forced harmonic oscillations was developed. For validation purposes, the roll damping coefficients calculated from the proposed method were compared with the experimental data obtained from a forced oscillation test and a free roll decay test. Then, CFD simulations were conducted with varying roll amplitudes and frequencies. At each frequency, the roll damping coefficients were divided into linear and nonlinear components using the linear regression analysis.

The obtained linear roll damping coefficients were compared with potential damping coefficients and showed a good agreement. The nonlinear (quadratic) damping coefficients were compared with those obtained by Ikeda's semi-empirical method and the two methods showed different trends. While the coefficients calculated using Ikeda's method remain relatively consistent, those from the proposed method showed a decreasing trend with frequencies. It was observed that the difference between the two methods origins from the frequency dependence of the eddy-making damping. Whereas Ikeda's method uses a constant eddy-making damping coefficient for different frequencies, the current CFD simulation showed decreases in vorticity with increasing frequency, which leads to decreasing eddy-making damping with frequency. Accordingly, the quadratic roll damping coefficients obtained from the proposed method show a decreasing trend a the frequency increases.

This study proposes a novel approach to determine the linear and nonlinear roll damping coefficients at varying frequencies. However, this study was only conducted for a simplified $2 \mathrm{D}$ section, therefore future pieces of work may be extending the proposed approach for a $3 \mathrm{D}$ ship, including other modes of motions. 


\section{Acknowledgement}

This work was supported by INHA UNIVERSITY Research Grant.

\section{References}

[1] Wawrzyński, W., \& Krata, P. (2016). On ship roll resonance frequency. Ocean Engineering, 126, 92-114. https://doi.org/10.1016/j.oceaneng.2016.08.026

[2] Uzunoglu, E., \& Guedes Soares, C. (2015). Automated processing of free roll decay experimental data. Ocean Engineering, 102, 17-26. https://doi.org/10.1016/j.oceaneng.2015.04.016

[3] Ribeiro e Silva, S., \& Guedes Soares, C. (2013). Prediction of parametric rolling in waves with a time domain non-linear strip theory model. Ocean Engineering, 72, 453-469.

https://doi.org/10.1016/j.oceaneng.2013.07.011

[4] Park, D.-M., Kim, Y., \& Song, K.-H. (2013). Sensitivity in numerical analysis of parametric roll. Ocean Engineering, 67, 1-12. https://doi.org/10.1016/j.oceaneng.2013.04.008

[5] Falzarano, J., \& Ul Mulk, M. T. (1994). Large amplitude rolling motion of an ocean survey vessel. Marine Technology and SNAME News, 31(04), 278-285.

[6] Francescutto, A., \& Contento, G. (1999). Bifurcations in ship rolling: experimental results and parameter identification technique. Ocean Engineering, 26(11), 1095-1123. https://doi.org/10.1016/S0029$\underline{\text { 8018(98)00061-4 }}$

[7] Spanos, D., \& Papanikolaou, A. (2009). Benchmark study on numerical simulation methods for the prediction of parametric roll of ships in waves (Vol. 2).

[8] Hu, K., Wang, R., Ma, S., Duan, W., Xu, W., \& Deng, R. (2017). Numerical modelling and study of parametric rolling for $\mathrm{C} 11$ containership in regular head seas using consistent strip theory. Brodogradnja, 68, 135-156. https://doi.org/10.21278/brod68309

[9] Bonfiglio, L., \& Brizzolara, S. (2013). Influence of Viscosity on Radiation Forces: a Comparison Between Monohull, Catamaran and SWATH. Paper presented at the The Twenty-third International Offshore and Polar Engineering Conference, Anchorage, Alaska. https://doi.org/

[10] Bonfiglio, L., \& Brizzolara, S. (2014). Unsteady viscous flow with non linear free surface around oscillating SWATH ship sections. WSEAS Trans. Fluid Mech, 9, 49-57.

[11] Faltinsen, O. M., \& Timokha, A. N. (2015). On damping of two-dimensional piston-mode sloshing in a rectangular moonpool under forced heave motions. Journal of Fluid Mechanics, 772, R1. https://doi.org/10.1017/jfm.2015.234

[12] Kristiansen, T., \& Faltinsen, O. M. (2010). A two-dimensional numerical and experimental study of resonant coupled ship and piston-mode motion. Applied Ocean Research, 32(2), 158-176. https://doi.org/10.1016/j.apor.2009.10.001

[13] Bonfiglio, L., \& Brizzolara, S. (2017). Amplitude Induced Nonlinearity in Piston Mode Resonant Flow: A Fully Viscous Numerical Analysis. Journal of Offshore Mechanics and Arctic Engineering, 140(1). https://doi.org/10.1115/1.4037487

[14] Roberts, J. B. (1985). ESTIMATION OF NONLINEAR SHIP ROLL DAMPING FROM FREE-DECAY DATA (Vol. 29).

[15] Roberts, J. B., Dunne, J. F., \& Debonos, A. (1994). Stochastic estimation methods for non-linear ship roll motion. Probabilistic Engineering Mechanics, 9(1), 83-93. https://doi.org/10.1016/0266-8920(94)90032-9

[16] Ikeda, Y., Himeno, Y., \& Tanaka, N. (1977). On eddy making component of roll damping force on naked hull. Journal of the Society of Naval Architects of Japan, 142(142), 59-69.

https://doi.org/10.2534/jjasnaoe1968.1977.142_54

[17] Ikeda, Y. H. Y. a. T. N., 1978. A Prediction Method for Ship Rolling, Osaka, Japan: Department of Naval Architecture, University of Osaka.

[18] Bass, D. W., \& Haddara, M. R. (1988). Nonlinear models of ship roll damping. International Shipbuilding Progress, 35(401), 5-24. doi:10.3233/ISP-1988-3540101

[19] Irvine, M., Longo, J., \& Stern, F. (2004). Towing tank tests for surface combatant for coupled pitch and heave and free roll decay motions.

[20] Kim, N., Kim, Y.-J. \& Ha, Y., 2015. Experimental Study of the Free Roll Decay Test for the Evaluation of Roll Damping Coefficients. Journal of the Society of Naval Architects of Korea, 52(6), pp. 460-470. https://doi.org/10.3744/SNAK.2015.52.6.460 
[21] Vugts, I. J., 1978. The Hydrodynamic coefficients for swaying, heaving and rolling cylinders in a free surface, Delft: Technical University Delft Report.

[22] Chen, H.-C., Liu, T., \& Huang, E. T. (2002). Time-domain Simulation of Large-amplitude Ship Roll Motions By a Chimera RANS Method. International Journal of Offshore and Polar Engineering, 12(03), 7.

[23] Wilson, R. V., Carrica, P. M., \& Stern, F. (2006). Unsteady RANS method for ship motions with application to roll for a surface combatant. Computers \& Fluids, 35(5), 501-524. https://doi.org/10.1016/j.compfluid.2004.12.005

[24] Yang, B., Wang, Z.-c. \& Wu, M., 2012. Numerical Simulation of Naval Ship's Roll Damping Based on CFD. Procedia Engineering, 37(1), p. 14 -18. https://doi.org/10.1016/j.proeng.2012.04.194

[25] Irkal, M. A., Nallayarasu, S. \& Bhattacharyya, S. K., 2014. EXPERIMENTAL AND CFD SIMULATION OF ROLL MOTION OF SHIP WITH BILGE KEEL. Chennai, India., International Conference on Computational and Experimental Marine Hydrodynamics.

[26] Gu, M. et al., 2015. Numerical Simulation of the Ship Roll Damping. Glasgow, UK, International Conference on the Stability of Ships and Ocean Vehicles

[27] Sarkar, T., \& Vassalos, D. (2000). A RANS-based technique for simulation of the flow near a rolling cylinder at the free surface. Journal of Marine Science and Technology, 5(2), 66-77. https://doi.org/10.1007/s007730070012

[28] Yeung, R., Roddier, D., Alessandrini, B., Gentaz, L., \& Liao, S. (2001). On roll hydrodynamics of cylinders fitted with bilge keels. Paper presented at the Twenty-Third Symposium on Naval HydrodynamicsOffice of Naval ResearchBassin d'Essais des CarenesNational Research Council.

[29] Kakar, K. (2002). Computational Modeling of FPSO Hull Roll Motions and Two-component Marine Propulsion Systems. Austin, Texas: Ocean Engineering Group, The university of Texas at Austin.

[30] Henning, H. L. (2011). A numerical investigation into the heave, sway and roll motions of typical ship like hull sections using rans numerical methods. Stellenbosch University South Africa.

[31] Bonfiglio, L., Brizzolara, S. \& Chryssostomidis, C., 2012. Added Mass and Damping of Oscillating Bodies: a fully viscous numerical approach. Harvard, Cambridge, USA, Proceedings of the 9th WSEAS International Conference on FLUID MECHANICS (FLUIDS '12).

[32] Thilleul, O., Babarit, A., Drouet, A., \& Le Floch, S. (2013). Validation of CFD for the Determination of Damping Coefficients for the Use of Wave Energy Converters Modelling. (55430), V009T012A032. https://doi.org/10.1115/OMAE2013-10818

[33] Kwon, S. H., Kim, B. J., Han, S. Y., Kim, Y. J., Ahn, K. S., Ren, D., . . Chen, X. B. (2014). Study on roll damping around a circular cylinder. Paper presented at the the 29th Intl Workshop on Water Waves and Floating Bodies, Osaka, Japan

[34] Y1ldı, B., 2016. URANS prediction of roll damping for a ship hull section at shallow draft. Journal of Marine Science and Technology, 21(1), pp. 48-56. https://doi.org/10.1007/s00773-015-0331-4

[35] Lavrov, A., Rodrigues, J. M., Gadelho, J. F. M., \& Guedes Soares, C. (2017). Calculation of hydrodynamic coefficients of ship sections in roll motion using Navier-Stokes equations. Ocean Engineering, 133, 36-46. https://doi.org/10.1016/j.oceaneng.2017.01.027

[36] Yıldı, B., Sener, B., Yurtseven, A., \& Katayama, T. (2019). NUMERICAL AND EXPERIMENTAL CALCULATION OF ROLL AMPLITUDE EFFECT ON ROLL DAMPING. Brodogradnja, 70, 1-15. https://doi.org/10.21278/brod70201

[37] Journée, J. M. J. (2001). Theoretical Manual of SEAWAY (S. Laboratory, Trans.). Delft, Netherlands: Delft University of Technology

Submitted: $\quad$ 11.09.2019. Soon-Seok Song

Department of Naval Architecture, Ocean \& Marine Engineering, Faculty of

Accepted: $\quad$ 03.10.2019. Engineering, University of Strathclyde, Glasgow, UK

Sang-Hyun Kim (corresponding author), kimsh@inha.ac.kr

Department of Naval Architecture and Ocean Engineering, Inha University, Incheon 22212, Republic of Korea

Kwang-Jun Paik

Department of Naval Architecture and Ocean Engineering, Inha University, Incheon 22212, Republic of Korea 